\title{
Fragmentation And Segmentation: Marketing Global Benefits
}

Russell Adams, University of Texas at Brownsville, USA

\begin{abstract}
Though consumption culture and globalization are major themes impacting the modern landscape, there has been limited research in these areas due to, in part, the increasing fragmentation of markets. A case is made that the seemingly disparate views, cultural fragmentation and global segmentation can be harmonized. This paper presents a theoretical framework to understand how the fragmentation of markets and global segmentation strategies can be compatible. Due to the cultural convergence brought on by globalization and marketing intermediaries, global segments can be identified through the common needs sought by consumers.
\end{abstract}

Keywords: Globalization; Consumption; Brands; Market Segmentation

\section{INTRODUCTION}

lobalization of markets has been an ongoing debate since Levitt's (1983) argument for standardization. There are two major opposing arguments at work: 1) There is increasing homogeneity of markets or 2) markets are becoming more fragmented. The argument of this paper is that due to the increasing spread of technology and media, there are homogenous groups of consumer segments that transcend country boundaries (Sheth and Parvatiyar, 2001) and that this, in turn, harmonizes the two arguments when one recognizes that if segments are understood by the benefits sought by the consumers when can then create segments from the fragmented groups. This paper will attempt to justify this argument by reviewing the impacts of globalization on consumption culture, brands' roles in creating and satisfying needs, and subsequently, the need for a new understanding of market segments.

\section{FRAGMENTATION, SEGMENTATION AND NEEDS}

By viewing different cultures and population around the world, it may be noticed that people's needs and aspirations are similar. People, in general, may be more alike around the world than different, and this is especially true when one looks at peoples' interests as people with similar interests gravitate toward each other, irrespective of nationality. Although studies, such as Hofstede (1992) and Trompenaars (1997), note that countries are found to be different on certain aspects, such as locus of control, time perspective, and risk, these generalist macro views are not actually useful for marketers (Mahlhotra et al 1998). Why? Because marketers do not market to countries as a whole, but to the members of consumer segments within those countries. It is the contention of this paper that there are consumer segments that span cultural, geographic, and political boundaries and that the segments share more in common with each other than with countrymen who are not in the segment. Marketing is shifting to become integrated globally, as opposed to seeking cross-country differences, and the goal is now to discover transnational similarities. One advantage of this is that it is less contextually bound and therefore has greater potential for theory development. Sheth and Parvatiyar (2001) subsequently allows for greater ability to apply results as target markets should be sought not within countries, but on a global basis (Sheth and Eshghi, 1989, and Ohmae, 1980)

Despite the importance of consumer behavior and globalization, there have been limited global studies of the two concepts in combination (Jain, 1989; Levitt, 1981; Levitt, 1983; and Taylor, 2005). Hofstede, et al (1992, 1999, 2002) and Steenkamp, et al $(1998,2000,2002,2003)$ have been the most active authors in cross border segmentation, but to date there have been no studies of multiple countries based on benefit segmentation, nor that 
have studied country level and domain-specific variables together (Steenkamp and Hofstede, 2002). In their book on global marketing, Hassan and Blackwell (1994) justify the value of global segmentation but point out that segmentation research still relies either on country-specific factors or consumption lifestyle factors, not a combination of the two. They also identify two global consumer segments - the global elite and global teen segments - arguing that these segments respond similarly in different markets. The argument of this paper is that there are additional segments that demonstrate marked similarities, including the poor and especially the middles classes (Savage et al. 1992).

After an extensive review of the literature, no research on cross-border benefit segmentation was found. Most benefit segmentation studies found are related to the tourism industry or other specific service markets, despite the fact that Greenberg and McDonald (1989) argue that need/benefit segmentation is superior to other forms of market segmentation and has stood the test of time (Green 1985). This paper heeds the call for greater macro cultural studies in marketing and consumer behavior (Cornwell and Drennan, 2004, and Firat, 1985).

When we look at marketing research, the theme of focusing on differences is apparent. It appears that the main thrust of research is to determine the differentiation of customers to the point that we determine that every customer is a customer of one and shares absolutely no traits with any other customers. This line of reasoning does nothing for marketing because it then becomes unworkable and also continues the isolation of the consumer from others, thereby reinforcing the tension of the other and the unknown. Too much in marketing is written temporally and quickly loses its relevance (Firat, 1985). We focus on the trivial and easily observable; that is; buyer behavior, not consumer behavior, without taking the time to look at the underlying factors and motivations that are actually driving behavior (Firat, 1985, and Firat and Dholakia, 1982). The common search for predictability and correlation, without understanding the true nature of the relationship, Bourdieu (1984) has led marketing research to its current predicament of being unable to explain consumer behavior (Taylor, 2005, and Vargo and Lusch, 2004).

This is not the first attempt to understand underlying common factors. Studies such as Hofstede (1992) and Trompenaars (Trompenaars and Turner, 1997) note that nationalities are generally different in aspects, such as locus of control, time perspective, risk, information processing, masculinity and individualism, leading many to conclude that these are appropriate for segmentation. The problem is that these generalist views are not actually useful for marketers. Why? Simply because marketing to a nation, as if it were composed of all the same personality type, is not realistic. It does not acknowledge the existence of separate market segments. Focusing on the markets and personalities that are border-free is both more lucrative and more logical. For example, many view rich and poor Chinese as being more similar than a rich American and a rich Chinese; however, it is more likely that these rich buyers share more in common with each other than the average individual from their respective countries. Luxury buyers in the US and China share more behavioral similarity with each other (Hassan and Katsanis, 1994) than they do with their own countrymen. As we know in marketing, behavior is more important than attitudes, yet multicultural marketing research focuses on the attitudes that cultures create. A heuristic the author uses is that friendships are started by finding something in common with those we encounter. From this base of shared experience, we can then build a relationship that allows us to celebrate our differences. Marketers should attempt to do the same. This is becoming increasingly pertinent in the modern era (or "Post Modern Era") of globalization and the diffusion of modern consumerism to every corner of the globe. By acknowledging this concept, we can realize that there are bands, or segments, of people around the world that share and express similar ideas and exhibit similar behavior regardless of their nation of birth and their supposed culture. There are potential global communities that marketing can aid in linking these groups to form a sense of community.

Firat's (1997) concept of the fragmentation of markets is helpful at this point. The fragments he discusses represent groups of consumers that are separating themselves from the mainstream and forming their own communities based on different aspects of non-geographically specific ideologies. These groups may also coalesce around products or objects, but the group members imbue their own meanings into the products (Derrida, 1994). These fragments are then forming new communities that are constructed from both global and local beliefs and ideologies. The lumping of heterogeneous country-based groups into one segment, such as described in Hofstede's (1992) original landmark work, does not reflect the realities of the global markets and therefore lack meaningful value in researching global consumers (Dickson and Ginter, 1987). The historic methodology of marketing to the lowest common denominator and creating increasingly generic products rests on similarly unhelpful marketing 
methodologies. People may seek similar benefits, but the expression of these benefits may vary. It is this difference in benefits sought that forms a basis for segmentation that marries the value of understanding the commonality of groups while allowing for the differences between these groups that exist; i. e., homogenous groups among a heterogeneous whole.

\section{CONSUMERISM}

Consumption is a function of production (Baudrillard, 1988; Featherstone, 1990; and Firat and Dholakia, 1982). As factories and the means of production have shifted to other nations, so has the need to involve the labor force in the trappings of consumption. Through marketing we assist in forming what consumers' determine believe their needs are and to keep them working those needs can only be satisfied through the market which requires money and hence the desire to participate in the production function. As production spreads, so does both the economic capability to consume and the motivation to do so.

Consumerism is one of the most important and pervasive aspects of globalization and can be found in every country in the world (Baudrillard, 1988; Featherstone, 1990; and McCracken, 1986) and is a substantial field of study (Arnould and Thompson, 2005). Many may decry the Westernization of the world, as this is what consumerism is considered to lead to. Pollay (1986) speaks of advertising as having a nefarious influence on the world by "reinforcing materialism, cynicism, irrationality, selfishness, anxiety, social competiveness, sexual preoccupation, powerlessness and loss of self respect" (Pollay, 1986). This is essentially the pessimist view of advertising and, by association, consumerism. Also Ritzer's "Globalization of Nothing" (Ritzer, 2005) captures the diminishing role of institutions and the rise of global consumption values to the detriment of local and indigenous institutions. Norberg-Hodge (2003) complains that globalization and its formation of a monoculture is leading to increased violence. However, one must ask, "If the messages are so evil, why are they so successful in infiltrating cultures around the world?" Consumerism has long been recognized as part of Western economies, but it is also now being seen in emerging economies. One clue to consumerism's power is mentioned in Pollay's (1986) critique when he refers to Berman's (1981) observation that the institutions of family, religion and education have become noticeably weaker in society, specifically over the last three generations. The inference made is that advertising and consumption culture are the influences that are weakening these institutions. Could it be, however, that these institutions are weakening because of the changing nature of society and that consumerism is just filling the vacuum? Could it be that consumerism is a result of the decreased pertinence of these institutions in the modern world as opposed to the cause of their failure? Cultures are dynamic and if shared beliefs of a culture no longer provide the answers or lose their utility, they ought to fade away and be replaced by more robust ideologies. The main complaint of these authors is that the old cozy set of institutions and rules is being replaced by new institutions that acknowledge new ideals. This is not to deny that the family, education, religion and nationalism are dead ideologies; it is just that consumerism is another, increasingly important, ideology on the menu from which people choose to use. A belief in one institution or ideology does not necessarily preclude the value of other ideologies.

The result of the broadened affluence and increased telecommunications is that people are now exposed to different views of the world. They are no longer indoctrinated solely in their own cultural systems, but also of those found around the world. From these different world views, one can pick and choose those aspects that are most appealing. When we see the implications for products and their consumption, we see that people play with products and brands, not as advertisers sell them, but to an extent people manipulate the meanings of brands and products so that they exist comfortably within their newly developed meaning systems. This is the emancipation. Consumers now have the choice of what group they want to belong to and how they want to define their lives. They are no longer limited to the institutions established in their own countries.

\section{CONSUMPTION CULTURE AND STATUS}

Consumption culture has been a topic of interest for marketers, sociologists and anthropologists alike. As a result of this, there is a rich body of literature. In this section, the history of consumption will be reviewed and this will be linked to its role in class structure and lifestyles. Ultimately, it will be shown that this combination results in the non-utilitarian consumption benefits sought by consumers and not just in the modern Western world, but in developing markets as well. 
In his book "Culture and Consumption" (1988), Grant McCracken provides a very concise review of the history and advent of consumption culture dating back to the 1600's and the actions of Queen Elizabeth that led to the form of consumption culture that we see today. In essence, Queen Elizabeth began a process of ostentatious consumption for the purposes of political control by making extravagant consumption the prime hallmark of status. McCracken also notes that consumption and culture are inextricably joined in an iterative process; so, in essence, consumption and culture must be studied together. This role of conspicuous consumption has been studied notably by Veblen (1899) and more recently by Bourdieu in "Distinctions" (1984). The critical connection between these studies is the political nature of consumption and its role in establishing status. It is a natural by-product of human society to establish status roles and material objects primarily to establish one's status. These studies both recognize the impact of consumption on culture and Bourdieu discusses that cultural mediators, such as marketing operatives, form the basis of consumption and hence culture. McCracken (1988) presents a model whereby the culturally constituted world starts with the media, fashion and advertising industries, and passes through consumer goods to the individual consumer. With the ever-increasing propagation of Western style consumption, it follows logically that the goods that establish status in Western societies will also find a role in those societies that are exposed to Western media, and through the expansion of globalization to all corners of the earth, only a few primitive societies remain isolated.

More importantly, as Friedman points out in "Cultural Identity and Global Process" (1994), cultures cannot be studied in isolation because as cultures interact, they also impact one another and must be studied concurrently. This thesis recognizes this by viewing consumer culture from a global perspective and aims to demonstrate that the cultural process of consumption is manifested with equivalence among the demographically and geographically diverse global population. This is expanded in Ritzer's "Globalization of Nothing" (2004) which remarks that rapid globalization has led to the presence of "nothing" in even underdeveloped nations ("Nothing" is described as centrally-controlled products that have no substantive meaning - an extension of the concept of standardization.) Ritzer does not say that this is necessarily bad but that it does exist.

One of the reasons that goods and culture are linked is that goods, in many cases, are the substantiation of culture (McCracken, 1986, 1988) and class (Belk, Mayer and Bahn, 1981, and Coleman, 1983). For the above reasons, it is reasonable to understand culture through the goods that people purchase and the purposes for which they consume these goods.

\section{CULTURAL CONVERGENCE: MEDIA AND CULTURAL INTERMEDIARIES}

Bourdieu's (1984) classification of a dominant class can be applied to the convergence of cultures due to globalization and the media. Increasingly the dominant class, and hence the dominant values espoused, are of Western-oriented consumption. Much of this can be attributed to the work of cultural intermediaries which increasingly are found in media (Lury, 1996) and whose scope is increasing due to the expansion of media outlets on a global basis.

Cultural intermediaries, a coin termed by Bourdieu (1984), are used because it captures the essence of what media's function is in defining the products we seek. Initially, Bourdieu outlined that it was the children of the bourgeoisie that tended to enter these fields in the 60's and 70's as increased educational opportunities had decreased the distance between the classes, and this mechanism was a means to maintain control of that which is aesthetic. Negus (2002) expands on the concept that Bourdieu first described and relates it to contemporary culture and media and to the connection between consumption and production. The cultural intermediaries' purpose is to shape the symbolism of what we desire, and the media plays a critical role in this symbolism through representations and advertising (Holt, 2004; Wernick, 1991; and Featherstone, 1991). Cronin (2004) further expands this theme by focusing on advertising practitioners but argues that they are merely reacting to commercial imperatives rather than consciously changing culture. Needless to say, media plays an important role in guiding people's sense of fashion and taste. 


\section{BRAND}

Brand carries important values for global consumerism. Brands are mental maps conveying rich information - awareness, attributes, benefits, images, thoughts, feelings, attitudes and experiences (Keller, 2003). There has been much research about brands but little research linking brands to global segmented communities (Taylor, 2005). Muniz and O'Guinn's (2001) work on brand communities is a start down this path, but this study was limited to a domestic framework. This work was extended by McAlexander, Schoueten, and Koenig (2002) with an eye to explaining the dynamic relationships of the brands, people, objects and the marketers themselves. This demonstration that communities can be created without regard to geography fits in well with the idea that these communities could be found globally if we were to look for them. One of the primary purposes of a company's investment in brand capital is to convey this message of trust and safety. Brands also increase one's sense of belonging. Brands, and brand communities, create the framework for belonging. Steenkamp, Batra and Alden (2003) find that people's tastes and needs are converging around the globe, especially in reference to brands.

This convergence is pertinent to the idea of consumerism's success and globalization because it can help explain the success of global brands in all corners of the world. Holt (2004) explains how brands become iconic, and one of his principle arguments for successful icons, especially Coca Cola, is that they tap into widely held consumer tensions and bring people together with a sense of community. Globalization has itself created many social tensions along with the spread of democracy, economic reform, and increasing affluence. The world is changing rapidly with the aid of telecommunications and people are recognizing that they are not alone. Brands are helping create communities of like-minded individuals across the globe, with segments of people adopting the messages of the brands that resonate with them. Another advantage of brands is that they are flexible and through their intangibility, adaptive (Roth, 1995). People can mold brands and their possessions into forms that they can relate to and, with this, create a collage of brands that become reflections of themselves or who they want to be (Belk, 1988, and Holbrook and Hirschman, 1982).

\section{CONCLUSION: GLOBALIZATION AND MARKET SEGMENTATION}

Globalization is considered to be the presence of the same lifestyles, products, consumption patterns, and cultural experiences across the globe, across many economically affluent or economically poor countries of the world (Firat, 1997, p. 78).

In the broadest sense, the term globalization seems to capture the idea that borders are diminishing in importance. When we understand that the political system in the modern sense is giving way to economics and the market, we see the dominance of the markets. It is the spread and intersection of these markets across political and nationalistic or ethnocentric cultures that are being described with globalization. Therefore, globalization, by this definition, links directly to the idea of global market segments.

Steenkamp and Hofstede (2002), in an extensive review of segmentation literature, found only 11 studies that deal with international market segmentation. They remark that this is due to the difficulty in conducting the research both theoretically and structurally; however, this research stream is fruitful and feasible. It offers a solution to the standardization and adaptation debate and can be effective in implementation. Studies have either been country-level segmentation or domain-specific segmentation, but not both. A more appropriate method is to combine country level and consumer-specific responses to create a framework that explains richer, more actionable information.

If one also accepts the Post Modernist shift's (Firat and Venkatesh, 1993) impact on consumers, whereby people are developing multiple ideologies and views other than those traditionally followed, we can see that this view reflects more realistically what is occurring in the world of the multinational global economy. Hence, if companies want to be successful, they need to recognize the dominance of global consumers (Ohmae, 1991). This is not to say that we can ignore country borders as they act as a constraint, primarily for political and legal reasons; but in our process of identifying our potential customers, we should be blind to their location and only study the country-specific constraints once the target segment has been identified. Currently, the process is to start at the country level and then identify the customers (Steenkamp and Hofstede, 2002). Marketers would be better served by 
reversing the process - identify customers and then look to the country level to determine if the constraints make reaching the market unfeasible.

\section{AUTHOR INFORMATION}

Russell Adams is a Professor of Marketing and International Business at the University of Texas at Brownsville. He received his MBA from Thunderbird and $\mathrm{PhD}$ from UT Pan Am. He has worked and traveled in over 60 countries. He has been published in several National and International Journals and has also won a Best paper award for his work. His research interests include globalization and consumption culture. E-mail: radams@utb.edu

\section{REFERENCES}

1. Arnould, Eric J. and Craig J. Thompson (2005), "Consumer Culture Theory (CCT): Twenty Years of Research," Journal of Consumer Research, 31 (March), 868-82.

2. $\quad$ Baudrillard, Jean (1988), Consumer Society. Stanford, CA: Stanford University Press.

3. Bearden, William O. and Michael J. Etzel (1982), "Reference Group Influence on Product and Brand Purchase Decisions," Journal of Consumer Research, 9 (2), 185.

4. Belk, Russell W. (1988), "Possessions and the Extended Self," Journal of Consumer Research, 15 (September), 139-168.

5. _ R, N, Mayer and Kenneth D. Bahn (1981), "The Eye of the Beholder: Individual Differences in Perceptions in Perceptions of Consumption Symbolism," in Advances in Consumer Research, 8, ed. Kent Monroe, Ann Arbor, MI: Association for Consumer Research

6. Berman, Ronald (1981), Advertising and Social Change. Beverly Hills, CA: Sage.

7. Bourdieu, Pierre (1984), Distinction: A Social Critique on the Judgment of Taste. US: President and fellows of Harvard College Routledge and Kegan Paul Ltd.

8. Coleman, Richard P. (1983), "The Continuing Significance of Social Class to Marketing". Journal of Consumer Research, 10 (3), 265.

9. Cornwell, T. Bettina and Judy Drennan (2004), "Cross-Cultural Consumer/Consumption Research: Dealing with Issues Emerging from Globalization and Fragmentation," Journal of Macromarketing, 24 (2), 108.

10. Cronin, Anne (2004) Advertising Myths: The Strange Half-Lives of Images and Commodities, London \& New York: Routledge.

11. Derrida, Jacques (1994), Specters of Marx, the State of Debt, the Work of Mourning, and the New International (Peggy Kamuf, Trans.): Routledge.

12. Dickson, Peter and James Ginter (1987), "Market Segmentation, Product Differentiation, and Marketing Strategy," Journal of Marketing, 51 (April), 1-10.

13. Featherstone, Mike (1990), "Perspectives on Consumer Culture," Sociology, 1 (5-22).

14. Firat, A. Fuat Ed. (1985), Ideology vs. Science in Marketing. Greenwich, CT: JAI Press.

15. (1997), "Globalization of Fragmentation - A Framework for Understanding Contemporary Global Markets". Journal of International Marketing, 5 (2).

16. _ _ and Nikhilesh Dholakia (1982), "Consumption Choices at the Macro Level," Journal of Macromarketing, 2 (2 (Fall)), 6-15.

17. _ and Alladi Venkatesh (1993), "Postmodernity: The Age of Marketing," International Journal of Research in Marketing, 10, 3 (August), 227-249.

18. Friedman, Jonathon (1994) Cultural Identity and Global Process. London: Sage

19. Green, Paul (1985), "Quick and Simple Benefit Segmentation". Journal of Advertising Research, 25, (3): 9

20. Greenberg, Marshall, McDonald, Susan Schwartz. (1989) "Successful Needs/Benefits Segmentation: A User's Guide." The Journal of Consumer Marketing. 6, (3):29

21. Hassan, Salah and Roger Blackwell (1994), Global Marketing: Perspectives and Cases. New York: The Dryden Press.

22. Hassan, Salah and Lea Prevel Katsanis Eds. (1994), Global Market Segmentation Strategies and Trends. Structures and Strategies: International Business Press.

23. Hofstede, Geert (1992), Cultures and Organizations: Software of the Mind. New York: McGraw-Hill.

24. Jan-Benedict E.M. Steenkamp, and Michel Wedel (1999), "International Market Segmentation Based on Consumer--Product Relations," Journal of Marketing Research, 36 (1), 1-17. 
25. _ Michel Wedel, and Jan-Benedict E. M. Steenkamp (2002), "Identifying Spatial Segments in International Markets," Marketing Science, 21 (2), 160-77.

26. Holt, Douglas B (2004), How Brands Become Icons: The Principals of Cultural Branding. Boston, MA: Harvard Business School Press.

27. Jain, Subhash C. (1989), "Standardization of International Marketing Strategy: Some Research Hypotheses," Journal of Marketing, 53 (1), 70.

28. Keller, Kevin (2003), "Brand Synthesis: The Multideimensionality of Brand Knowledge," Journal of Consumer Research, 27 (March), 595-600.

29. Levitt, Theodore (1981), "Marketing Intangible Products and Product Intangibles," Harvard Business Review, 59 (3), 94.

30. _ (1983), "The Globalization of Markets," Harvard Business Review, 61 (3), 92.

31. Lury, Celia (1996), Consumer Culture. New Brunswick, New Jersey: Rutgers University Press.

32. McAlexander, John Schouten James H., and Harold F. Koenig (2002), "Building Brand Community," Journal of Marketing, 66 (January), 38-54.

33. McCracken, Grant (1986), "Culture and Consumption: A Theoretical Account of the Structure: A Theoretical Account of the Structure and Movement of the Cultural Meaning of Consumer Goods," Journal of Consumer Research, 13 (1), 71.

34. Muniz, Albert and Thomas O'Guinn (2001), "Brand Community," Journal of Consumer Research, 27 (March), 412-32.

35. Negus, Kevin. (2002). "The Work of Cultural Intermediaries and the Enduring Distance Between Production and Consumption." Cultural Studies, vol. 16, n ${ }^{\circ}$ 4, p. 501-515

36. Ohmae, Kenichi (1990), “The Borderless World”, Harper Business, New York, NY.

37. (1991), "Managing in a Borderless World," in Robert D. Buzzell, John A. Quelch and Christopher Bartlett, Global Marketing Management, Reading, MA: Addison-Wesley.

38. Pollay, Richard (1986), "The Distorted Mirror: Reflections on the Unintended Consequences of Advertising," Journal of Marketing, 50 (5), 18-36.

39. Ritzer, George (2005), "The Globalization of Nothing”. Riverside, CA: Sage.

40. Roth, Martin S. (1995), "Effects of Global Market Conditions on Brand Image Customization and Brand Performance," Journal of Advertising, 24 (Winter), 55-75.

41. Savage, Michael, Tony Fielding, James Barlow, and Peter Dickens (1992), Property, Bureaucracy, and Culture: Middle-Class Formation in Contemporary Britain. London; New York: Routledge.

42. Sheth, J.N., and Atul Parvatiyar (2001) "The Antecedents and Consequences of Integrated Global Marketing", International Marketing Review, 18, (1):16-29.

43. Eshghi, A. (Eds) (1989), Global Marketing Perspectives, Southwestern Publishing Company, Cincinnati, OH.

44. Steenkamp, Jan Benedict, Rajeev Batra and Dana L. Alden (2003), "How Perceived Brand Globalness Creates Brand Value," Journal of International Business Studies, 34(1), 53-65.

45. Hofstede, F. (2002), "International Market Segmentation: Issues and Perspectives." International Journal of Research in Marketing. 19, 185-213.

46. _ and S.M. Burgess, (2002), "Optimum Stimulation Level and Exploratory Consumer Behavior in an Emerging Consumer Market". International Journal of Research in Marketing 19 (2) pp. 131-150.

47. Taylor, Charles, R. (2005), "Moving International Advertising Research Forward: A New Agenda," Journal of Advertising Research, 34 (1), 7-16.

48. Trompenaars, Fons and Charles Hampden Turner (1997), Riding the Waves of Culture: Understanding Cultural Diversity in Business. Burr Ridge, IL: Irwin.

49. Vargo, Stephen L. and Robert F. Lusch (2004), "Evolving to a New Dominant Logic for Marketing," Journal of Marketing, 68 (January), 1-17.

50. Veblen, Thorstein 1970 (1899) The Theory of the Leisure Class. London: Unwin Books

51. Wernick, A. (1991) Promotional Culture: Advertising, Ideology and Symbolic Expression, London: Sage. 
NOTES 